\title{
Delusions: between Phenomenology and Prediction. Introduction
}

\author{
Przemysław Nowakowski ${ }^{1}$ \\ Centre for Philosophical Research in Warsaw \\ pnowakowski[]avant.edu.pl \\ Received and accepted December 2014; published winter 2014/2015.
}

Etendant les mains hors du lit, Plume fut étonné de ne pas rencontrer lemur : „Tiens, pensa-t-il, les fourmis l'auront mangé...” et il se rendormit. ${ }^{2}$

[Henri Michaux. 1930. Un certain Plume]

\section{Introduction}

A few years ago (while researching embodied cognition) I focused for some time on disorders of experience, which affect representation or beliefs regarding one's own body. One of the most fascinating and dramatic disorders was somatoparaphrenia (sometimes also astomatognosia) (Feinberg 2002). This disorder is when the patient believes that, for example, his hand is his aunt's or wife's hand. Or he believes it to be an inanimate object or a pet.

When I presented this issue during one a seminar pertaining to philosophy (not cognitive studies or psychiatry), I was met with disbelief. How is it possible for a person who is sound and rational in any other matter to be convinced that his or her hand is somebody else's hand? Where does this belief come from? Why can the person not be convinced that he or she is wrong? Is it possible for a rational person to allow himself or herself such strange beliefs and, additionally, to have them for a long time in spite of so much accounting against the beliefs (Freeman et al. 2004)? After all, such a belief should be accompanied by a serious disturbance in thinking, not limited to this one (bodily) realm, and so on ${ }^{3}$.

\footnotetext{
${ }^{1}$ language edition: Ewa Bodal.

${ }^{2}$ Stretching his hands out from the bed, / Plume was surprised not to encounter the wall. / "Hmm!" he thought, "The ants musthave eaten it..." and he went back to sleep. (H.M., Plume, transl. D. Ball)

${ }^{3}$ Such a problem pertains to monothematic delusions.
} 
Such a strong reaction seemed very intriguing to me. This issue of AVANT was created in order to present the notion of delusions-what they are and how they are currently explained-in a more detailed manner.

It was important to me that the articles should study delusions from various perspectives, so as to achieve a complete picture of the current state of research. It did not all work out. Many subjects have not been addressed (they will be mentioned at the end of the introduction), but the works we present contain some of the most interesting and dynamically developing notions in research on delusions.

\section{Contents of the Issue}

One of the leading and central figures in research on delusions, Max Coltheart $^{4}$ (see Coltheart et al. 2011), presents and summarises his heretofore work in a short text. Miyazono and Bortolotti present an interesting argument aimed at the charges against the doxastic concept of delusions (Bortolotti 2010). Adams, Brown and Friston showcase a predictive-Bayesian concept of delusions (see also Corlett et al. 2009; 2015). Young criticizes the current changes in the two-factor account of delusions and argues that the role of experience should not be dismissed within it. Kapusta presents an interesting, phenomenological approach to delusions, rooted in the classic works of Karl Jaspers (1913/1997).

In the last article, Carruthers takes a look at delusions from a different perspective. He uses them in order to show the weakness of the sense of agency concept as proposed by Wegner (2002). The issue also contains an interview with Jakob Hohwy. In Hohwy's still-recent book Predictive Mind (2013a), we can find an interesting, predictive approach to delusions (close to the one that Adams et al. present in the current volume of AVANT). Hohwy points towards the unobvious connections between delusions and illusions (see also Hohwy 2013b).

Let us take a closer look at the aforementioned articles.

In his summary/overview, Coltheart presents the development of his approach (the two-factor account of delusions), drawing attention to the neuropsychological research on delusions (the role of brain damage in the formation of delusions). He also addresses the differences between explaining monothematic and polythematic delusions (this differentiation is not analyzed in detail in the present volume). Additionally, he sketches the most promising issues in the current research on delusions.

\footnotetext{
${ }^{4}$ If the author's name is not otherwise annotated in the introduction, e.g. by the publication date, I am referring to a text published in the present issue of Avant.
} 
Adams, Brown and Friston highlight the role of precision of predictions in the formation of delusions. They show that "[t]his precision is thought to be encoded by postsynaptic gain of neuronal populations reporting prediction errors-the principal or pyramidal cells of superficial cortical layers" (this issue). They analyze the neurochemical mechanism responsible for the aforementioned precision, whose dysfunctions leads to false inferences, false learning, and changes in generative models that can be responsible for the formation of delusions. They point to the important role that active inference (one of the ways of updating beliefs in the predictive system) plays in this process.

Miyazono and Bortolotti show that the doxastic account of delusions (that is, the one claiming that delusions are beliefs), while popular among psychiatrists, seems particularly controversial for philosophers. They attempt a philosophical defense of this approach. They point out that that the strongest arguments against the doxastic account are (a) the argument from action guidance and (b) the argument from the causal role. Miyazono and Bortolotti claim that it is possible to refute these arguments. They show that many delusions guide actions, as well as weaken the role played by non-pathological beliefs in directing actions. Not every belief directs our actions. This is why they argue for the importance of the role of motivations (which is not taken into account by many critics). It is possible that the disorders of motivation are responsible for some delusions not directing our actions (see Bortolotti 2014). In the second case, they show that many delusions play the causal role of beliefs.

Young criticizes Coltheart et al.'s more recent works for removing the key role of experience in the formation of delusions, which, according to him, make it impossible to correctly explain the process. In this context, he discusses the differences between the endorsement and explanationist approaches to delusions (see also Bortolotti 2013). At the end of the work, he argues for the interactionist approach to delusions.

In his article, Kapusta highlights the specificity of a phenomenological approach to delusions. He puts particular emphasis on the roles of embodiment and intersubjectivity on the formation of delusions.

Carruthers argues that a good theory of awareness of action and sense of agency should explain the delusion of alien control (usually experienced by schizophrenics); no other theory can be a good theory of sense of agency and action. From this perspective, Carruthers criticizes Wegner's concept (2002).

Although particular authors present differing approaches to delusions, the remarks and threads visible in their articles frequently interweave. Kapusta discusses delusions using the Capgras and Cotard delusions as an example. These are also referred to in the works of Young (Capgras delusion) and 
Miyazono with Bortolotti (Cotard delusion). Adams et al. discuss in detail the predictive approach to delusions, but Miyazono and Bortolotti refer to this framing as a potential solution to the problems of the doxastic approach. Kapusta and Young focus on the role of experience in forming delusions, while Adams et al. and Carruthers discuss the connection between actions and delusions. These are only some of the threads connecting the articles showcased in the present volume.

\section{Further Research and Subsequent Views}

Further Research: As I have already mentioned, when conducting research into notions discussed in this volume, Miyazano (2014) and Bortolotti (2014) have published works that develop the doxastic approach to delusions, as well as the potential predictive framing of the mechanisms of delusion (Miyazono et al. 2014). Colthart with coworkers (Griffiths et al. 2014, 2015) have analyzed the relation between the two-factor approach and predictive approach. Adams (along with his past and current colleagues) adds subsequent elements to the predictive approach of the mechanisms of delusions (Adams et al. 2015; Moran et al. 2015; Perrinet et al. 2014; Vossel et al. 2014; Fitzgerald et al. 2014). The current issue of AVANT may be an excellent introduction to these works.

Subsequent Views: Obviously, not all interesting subjects could be touched upon in this short volume of AVANT. Besides Young's work, we have not devoted particular attention to specific examples of delusions (delusions of persecution, bodily delusions such as the aforementioned somatoparaphrenia, etc.). We have not analyzed the differences between monothematic and polythematic delusions, and we did not mention the very interesting issues of folie a deux and mass delusions (Langdon 2013). However, all this may be yet to come. Perhaps this is an opportunity to create another issue of AVANT devoted to delusions?

\section{Bibliography}

Adams, R. A., Aponte, E., Marshall, L. and Friston, K. J. 2015. Active inference and oculomotor pursuit: The dynamic causal modelling of eye movements. Journal of neuroscience methods. 242:1-14

Bortolotti, L. 2014. The epistemic innocence of motivated delusions. Consciousness and cognition, in print, http://dx.doi.org/10.1016/j.concog.2014.10.005.

Bortolotti, L. 2013. Delusion, The Stanford Encyclopedia of Philosophy, Edward N. Zalta ed.: URL = <http://plato.stanford.edu/archives/win2013/entries/delusion/>.

Bortolotti, L. 2010. Delusions and other irrational beliefs. Oxford University Press. 
Coltheart, M., Langdon, R., and McKay, R. 2011. Delusional belief. Annual review of psychology, 62: 271-298.

Corlett, P. R., Fletcher, P. C. 2015. Delusions and prediction error: clarifying the roles of behavioural and brain responses. Cognitive neuropsychiatry, 20(2): 95-105.

Corlett, P. R., Krystal, J. H., Taylor, J. R., and Fletcher, P. C. 2009. Why do delusions persist?. Frontiers in Human Neuroscience, 3:12.

Feinberg, T. E. 2002. Altered egos: How the brain creates the self. Oxford University Press.

FitzGerald, T. H., Schwartenbeck, P., Moutoussis, M., Dolan, R. J., and Friston, K. 2014. Active Inference, Evidence Accumulation, and the Urn Task, Neural Computations. 27(2): 306-328.

Freeman, D., Garety, P. A., Fowler, D., Kuipers, E., Bebbington, P. E., and Dunn, G. 2004. Why do people with delusions fail to choose more realistic explanations for their experiences? An empirical investigation. Journal of consulting and clinical psychology, 72(4): 671.

Griffiths, O., Langdon, R., Le Pelley, M. E., and Coltheart, M. 2014. Delusions and prediction error: re-examining the behavioural evidence for disrupted error signalling in delusion formation. Cognitive neuropsychiatry, 19(5): 439-467.

Griffiths, O., Le Pelley, M. E., and Langdon, R. 2015. The bridge between neuroscience and cognition must be tethered at both ends. Cognitive neuropsychiatry, 20(2): 106-108.

Hohwy, J. 2013a. The predictive mind. Oxford University Press.

Hohwy, J. 2013b. Delusions, illusions and inference under uncertainty. Mind \& Language, 28(1): 57-71.

Jaspers, K. 1913/1997. General psychopathology. JHU Press.

Langdon, R. 2013. Folie à deux and its Lessons for Two-Factor Theorists. Mind \& Language, 28(1): 72-82.

Michaux, H. 1994. Darkness Moves. An Henri Michaux Anthology, 1927-1984. Selected, translated, and presented by David Ball. University of California Press.

Miyazono, K. 2014. Delusions as harmful malfunctioning beliefs. Consciousness and cognition, in print. http://dx.doi.org/10.1016/j.concog.2014.10.008.

Miyazono, K., Bortolotti, L., and Broome, M. R. 2014. Prediction-error and two-factor theories of delusion formation. Aberrant Beliefs and Reasoning, ed. N. Galbraith. Psychology Press: 34-54.

Moran, R. J., Jones, M. W., Blockeel, A. J., Adams, R. A., Stephan, K. E., and Friston, K. J. 2015. Losing Control Under Ketamine: Suppressed Cortico-Hippocampal Drive Following Acute Ketamine in Rats. Neuropsychopharmacology, 40(2): 268-277.

Perrinet, L. U., Adams, R. A., \& Friston, K. J. 2014. Active inference, eye movements and oculomotor delays. Biological cybernetics, 108(6): 777-801. 
Vossel, S., Bauer, M., Mathys, C., Adams, R. A., Dolan, R. J., Stephan, K. E., \& Friston, K. J. 2014. Cholinergic Stimulation Enhances Bayesian Belief Updating in the Deployment of Spatial Attention. The Journal of Neuroscience, 34(47): 15735-15742.

Wegner, D. M. 2002. The illusion of conscious will. MIT press. 